\section{Processos de territorialidade Kaingang envolvendo a Terra Indígena Jamã Tÿ Tãnh, Estrela, Rio Grande do Sul, Brasil Territoriality Kaingang processes involving the Indigenous Land Jamã Tÿ Tãnh, Estrela, of Rio Grande do Sul state, Brazil}

\author{
Juciane Beatriz Sehn da Silva ${ }^{1}$ \\ Luís Fernando da Silva Laroque ${ }^{1}$ \\ Ernesto Pereira Bastos Neto ${ }^{1}$
}

DOI: http://dx.doi.org/10.20435/tellus.v0i31.425

Resumo: O território compreendido entre os atuais estados brasileiros de São Paulo, Paraná, Santa Catarina, Rio Grande do Sul e a Província de Misiones, na Argentina, pertence tradicionalmente ao povo Kaingang. Sempre fez parte da lógica Kaingang a movimentação pelo seu tradicional território a fim de desenvolver suas atividades de subsistência material e de reprodução social. A trajetória do grupo que atualmente constitui a Terra Indígena Jamã Tÿ Tãnh, localizada no município de Estrela, insere-se nessa lógica de movimentação espacial, através da qual existe uma relação de pertencimento com o espaço ocupado, na medida em que seus antepassados passaram pelo Vale do Taquari e, nesse espaço, deixaram as marcas de sua ocupação. O objetivo deste estudo será discutir os processos de territorialidade, sentidos e práticas pelos quais o grupo da Terra Indígena Jamã Tÿ Tãnh tem firmando sua relação de pertencimento com o atual espaço ocupado. Para tanto, o evento da duplicação da BR 386 que afeta diretamente o grupo em questão, trará importantes possibilidades de análise da questão estudada. Há toda uma relação de pertencimento dos Kaingang da Terra Indígena Jamã Tÿ Tãnh a essa região conhecida como Vale do Taquari, e o fato de ocuparem espaços em contextos urbanos e estabelecerem nele uma aldeia fixa não restringe suas tradicionais movimentações que sempre fizeram para satisfazer suas necessidades físicas e culturais.

Palavras-chave: Kaingang; movimentação espacial; reconhecimento; territorialidade.

\footnotetext{
${ }^{1}$ Centro Universitário Univates, Lajeado, Rio Grande do Sul, Brasil.
}

Sobre os autores:

Juciane Beatriz Sehn da Silva: Mestranda no Programa de Pós-Graduação em Ambiente e Desenvolvimento da Univates. Bolsista PROSUP-CAPES. Graduada em História pela Univates, Lajeado, Rio Grande do Sul, Brasil. E-mail: sehn@universo.univates.br

Luís Fernando da Silva Laroque: Doutor em História. Professor e pesquisador do Programa de Pós-Graduação em Ambiente e Desenvolvimento e do Curso de História da Univates. E-mail: Iflaroque@univates.br

Ernesto Pereira Bastos Neto: Bolsista de Extensão Univates. Graduando do Curso de Licenciatura em História. E-mail: ernesto.bastos@univates.br 
Abstract: The territory located between the current Brazilian states of São Paulo, Paraná, Santa Catarina, Rio Grande do Sul and Província de Misiones, in Argentina, has territorial areas traditionally belonging to the people Kaingang. It has always been part of the Kaingang logic move through their traditional territory in order to develop their subsistence material and social reproduction activities. The group trajectory which currently constitutes the Indigenous Land Jamã Tÿ Tãnh, located in the city of Estrela, Rio Grande do Sul, is part of this spatial movement logic, through which there is a belonging relationship with the space occupied, to the extent that their ancestors passed through the Vale do Taquari and in this space have left the marks of their occupation. The aim of this study is to discuss the territoriality processes, meanings and practices by which the group of the Indigenous Land Jamã Tü Tãnh has firming its relationship of belonging with the current space occupied. One observes that the (re) signification of the traditional practices of Kaingang territoriality, that will over the time acquiring new meanings, and these fit perfectly to the cultural standards of the group in question. There is a relationship of belonging of the Kaingang from the Indigenous Land Jamã Tÿ Tãnh to this region known as Vale do Taquari, and the fact that they occupy spaces in urban contexts, and establish in it a fixed village, does not restrict their traditional movements that have always made to satisfy their physical and cultural needs.

Key words: Kaingang; spatial movement; recognition; territoriality.

\section{INTRODUÇÃO}

No que se refere ao contato com as frentes de expansão enfrentado pelos antepassados dos Kaingang que hoje se fazem presentes no Vale do Taquari, entre eles os habitantes da Terra Indígena Jamã Tÿ Tãnh, podemos nos remeter principalmente à segunda metade do século XIX, quando o Estado Nacional Brasileiro adotara uma política de incentivo à imigração e colonização europeia massiva desse território que atualmente conhecemos como Rio Grande do Sul.

Entretanto nos parece relevante compreender o estabelecimento desses Kaingang em espaços que Laroque (2007) aponta como tradicional território Kaingang no século XIX. Segundo os estudos de Noelli (2000), com base em Lathrap (1970; 1977) e Brochado (1984), os Kaingang, assim como os Xokleng, fazem parte das populações de matriz cultural Jê, são originários do Centro-Oeste do Brasil e teriam migrado em direção ao sul em virtude de uma expansão populacional desde a Amazônia, ocorrida em função do avanço da agricultura e desenvolvimento de novas tecnologias, por volta de 2.500 anos atrás.

Nesse processo, não apenas migraram na direção ao sul grupos pertencentes ao tronco linguístico Jê, mas também de matriz Tupi, como por exemplo os Tupi-Guarani. Houve possivelmente contato entre essas sociedades, entretanto, segundo Noelli (2000), uma expansão populacional dos grupos 
Processos de territorialidade Kaingang envolvendo a Terra Indígena Jamã Tÿ Tãnh, Estrela, Rio Grande do Sul, Brasil

Tupi-Guarani teria feito com que se estabelecessem os grupos Jê, majoritariamente nas regiões altas, indo ao encontro das produções que dão conta da ocupação dos grupos Jê no Planalto Meridional brasileiro, que se estende da metade oeste do atual estado de São Paulo, passando por grande parte dos territórios de Paraná e Santa Catarina, metade norte do Rio Grande do Sul e Missiones, na Argentina.

O período colonial como um todo marca o desrespeito e o desinteresse dos colonizadores para com as sociedades indígenas, principalmente as não falantes de idiomas do tronco linguístico Tupi, como é o caso dos Kaingang. Frente a isto, segundo Becker (1995), os contatos com os indígenas Kaingang, principalmente nos séculos XVI, XVII e XVIII foram esparsos e não temos maiores registros sobre esse processo.

Segundo Vedoy (2015), foi com o intuito de legitimar o território do extremo-sul brasileiro como sendo português, em decorrência das instáveis disputas fronteiriças do território sul meridional com os espanhóis, e a fim de estimular a economia das charqueadas que se intensifica no final do século XVIII, a distribuição de sesmarias principalmente a chefes militares visando à ocupação territorial, é que as frentes de expansão do Projeto Colonial Português e posteriormente do Império Brasileiro se instalaram em territórios da Bacia Hidrográfica do Taquari-Antas. Ao longo dos séculos XVIII e XIX, essas frentes de expansão através de mecanismo como a distribuição de sesmarias, instalação de fazendas, bem como de colônias para imigração, atingiram diretamente os indígenas Kaingang. Salienta-se que, para os Kaingang, o território não é concebido somente para obtenção dos recursos de subsistência, mas também como um espaço de relações sociais, políticas e cosmológicas amplas e de complexo significado para a vivência Kaingang (LAROQUE, 2009).

As divergências causadas por esse contato interétnico motivaram guerras e alianças entre imigrantes alemães e facções Kaingang, levando o governo da Província do Rio Grande do Sul a recorrer, a partir de 1845, à política dos aldeamentos indígenas Kaingang em territórios próximos à Bacia do rio Uruguai. Segundo Nonnenmacher (2000), os três principais aldeamentos foram Guarita, Nonoai e Campo do Meio, os quais visavam ao confinamento dos indígenas Kaingang.

Essa política mostrou-se falha, na medida em que grupos que não aceitaram aldear-se - e seguiram vivendo à sua maneira, inclusive efetuando ataques a colonos -, tanto quanto grupos que se aldearam deixam claras evidências de que o fizeram a seu modo, e não mantiveram definitivamente suas parcialidades confinadas, demonstrando a continuidade do seu modo de vida e de suas movimentações sobre o território tradicional (LAROQUE, 2009). 
Busolli (2015), em sua pesquisa sobre o contexto da reterritorialidade Kaingang nas Bacias Hidrográficas Taquari-Antas, aponta que, com o advento da República 1889, a questão indígena, já diretamente compreendida como fundiária, é delegada aos estados e, na lógica do positivismo difundido no Rio Grande do Sul, os indígenas teoricamente seriam assimilados pela sociedade, perderiam sua cultura, e se integrariam naturalmente aos modelos de trabalho e sociedade não índia. Entretanto os Kaingang do norte do estado seguem reagindo às invasões dos colonos em suas terras, de modo que a postura do governo também não muda, apesar da criação de órgãos de proteção indígena como o Serviço de Proteção aos Índios e Localização de Trabalhadores Nacionais (SPILTN), que se tornaria mais tarde apenas Serviço de Proteção aos Índios (SPI), e o pensamento segue fundado no desrespeito às configurações e lógicas sociais dessa população, além do uso abusivo da força repressiva.

Nesse contexto, entre as décadas de 1950 e 1960, de acordo com Silva (2011) e com base nos estudos de Gonçalves (2008), que a família de Manoel Soares, patriarca da Terra Indígena Jamã Tÿ Tãnh, remanescente das parcialidades lideradas por Doble e/ou Nicué, não teria aceitado estabelecer-se em aldeamentos durante a segunda metade do século XIX. Manoel Soares pertencia a um grupo de Kaingang que se manteve fora dos aldeamentos, em virtude da política repressiva praticada pelo governo estadual de Leonel Brizola entre 1959 e 1962, e se fixou na "Vila Macaco", que hoje se sabe é chamada de "Vila Santo Antônio" (EC, 17/03/2011, p.1) na cidade de Santa Cruz do Sul, RS, vivendo da venda de artesanatos e de serviços que prestavam à fumicultores locais. Seu Manoel veio a se "casar" com Dona Lídia, que era natural de Erneiras (Sinimbu), e depois com Dona Eva.

Por motivos da construção de um parque no lugar onde estavam estabelecidos, acabaram sendo obrigados a procurar um novo local para viver e sustentar-se. Nessa busca, tinham como objetivo encontrar o lugar onde o patriarca Manoel Soares guardava memórias de seus antepassados terem enterrado seu umbigo, local reconhecido pelo grupo como sendo a região do Vale do Taquari (SILVA, 2011).

O objetivo deste estudo será discutir os processos de territorialidade, sentidos e práticas pelos quais o grupo da Terra Indígena Jamã Tÿ Tãnh tem firmando sua relação de pertencimento com o atual espaço ocupado. Trata-se de uma pesquisa qualitativa e de caráter exploratório e indutivo. Na realização deste estudo, nos baseamos na revisão bibliográfica de livros, artigos, dissertações de Mestrado e teses de Doutorado. Também realizamos uma busca documental junto ao Ministério Público Federal de Lajeado, onde tivemos acesso a diversos documentos sobre a referida Comunidade Indígena, 
Processos de territorialidade Kaingang envolvendo a Terra Indígena Jamã Tÿ Tãnh, Estrela, Rio Grande do Sul, Brasil

tais como laudos antropológicos, pareceres, procedimentos administrativos, ofícios e acervos jornalístico. Além disso, nos utilizamos da metodologia de História Oral durante à pesquisa de campo na emã Jamã Tÿ Tãnh, realizada com dois Kaingang que, neste estudo, serão denominados como E1A e EC pelo fato de terem assinado o Termo de Consentimento Livre Esclarecido (TCLE), que resguarda a identidade dos entrevistados. Também utilizou-se de diários de campo elaborados durante a pesquisa, nos quais constam dados importantes sobre o cotidiano do grupo, seus anseios, lutas e conquistas. Os dados foram analisados com base em aportes teóricos de autores como Seeger e Castro (1979), Hall (1992), Mesquista (1994), Martins (1997), Oliveira (1996), Tommasino (2000; 2004), Sidekum (2003), Cabral (2007) e Geertz (2008).

\section{PRODUÇÃO DE TERRITÓRIO E MOBILIDADE ESPACIAL DOS KAINGANG DA TERRA INDÍGENA JAMÃ Tั̈ TÃNH}

A Terra Indígena Jamã Tÿ Tãnh constituiu-se a partir de um processo de movimentação do patriarca Manoel Soares com suas esposas e filhos, em busca de sustentabilidade e do local onde Manoel teria suas raízes. Isto se deve sobretudo pela memória das marcas deixadas pelos seus antepassados em territórios da Bacia Hidrográfica Taquari-Antas. Dessa forma, a memória constitui-se como elemento fundamental na busca desse lugar de origem, e marca a relocalização do grupo no Vale do Taquari.

A oralidade é fundamental para compreendermos o processo pelo qual o grupo da Jamã Tÿ Tãnh, na liderança de seu Manoel Soares, irá produzir seu território em contexto urbano. Na fala de uma de suas filhas, foi em busca do local onde seu pai tivera seu umbigo enterrado, que o grupo iniciou sua trajetória de retorno, passando por diversos municípios como São Sebastião do Caí, Montenegro e Venâncio Aires, até chegar a Bom Retiro do Sul (SILVA; LAROQUE, 2012). Este processo teve início em meados da década de 1960, sendo o grupo oriundo do município de Santa Cruz do Sul. Acredita-se que a família de Manoel Soares e de suas esposas teriam permanecido fora dos aldeamentos instituídos por políticas indigenistas desde o século XIX, por vezes até negando sua própria identidade.

Outra questão crucial para a mobilidade do grupo se deve à necessidade de produzir sua existência por meio de trabalhos temporários e da produção e venda de artesanato. Dessa forma, a busca por sustentabilidade torna-se fator preponderante para a migração dos Kaingang que virão a constituir a Terra Indígena Jamã Tÿ Tãnh. 
Ao estabelecer habitação próxima ao trevo de acesso a Bom Retiro do Sul, foram orientados pela polícia estadual a deslocar-se para uma área um pouco mais abaixo, onde produziram seu tradicional emã até meados de 2006. É importante salientar que, em 2002, o grupo é reconhecido pelo Conselho Estadual dos Povos Indígenas (CEPI) como pertencente à etnia Kaingang, o que lhes garante maior visibilidade como sujeitos de direitos por parte da Fundação Nacional do Índios (FUNAI) e do próprio CEPI, enquanto órgão governamental. Devido às condições precárias de suas moradias e ao espaço limitado, o grupo passa a reivindicar junto ao CEPI a ampliação da área de terras ocupada e a construção de novas moradias, o que se torna realidade em 2005. A construção das casas realizou-se no ano seguinte, sendo uma parceria de diversos programas estaduais (RS Rural Especial, Programa Indígena, Secretaria Estadual de Habitação e da Companhia Estadual de Energia Elétrica). Assim, os Kaingang da Terra Indígena Jamã Tÿ Tãnh movimentam-se novamente, dirigindo-se para uma nova área, em direção a oeste do espaço ocupado.

A memória da ocupação do local reconhecido por eles como "Aldeia Velha" está presente na oralidade do grupo e pode ser verificada na fala de uma das filhas de Manoel Soares, que inclusive nasceu nesse local. Nesse sentido, temos:

Eu já sou daqui, eu não vim de Santa Cruz! Eu nasci aqui, eu nasci na Aldeia Velha, eu só fui registrada em Bom Retiro. De Santa Cruz eu não cheguei a vim. De Santa Cruz vieram os meus irmão mais velho [...]. É a Maria Antônia, o Jair, o Altair, o Carlos, a Clarice, que faleceu, o Pedro Antônio também que é falecido, e o Xicão também, é José Alvício, [...] ele é de Santa Cruz, eu acho que é esses aí que são, que eu tô me lembrando é esses aí. E eu já sou daqui, da parte daqui de Estrela, da Aldeia Velha [sic]. (ENTREVISTA 1A, 10/02/2016, p. 01).

Sabemos que o lugar de nascimento torna-se, na cultura Kaingang, um local de grande importância, pois marca a ocupação do espaço a partir da prática de enterramento do umbigo. A entrevistada nos revela também que, quando habitavam a "Aldeia Velha", podiam banhar-se e pescar na sanga, bem como produziam pequenas roças e viviam do artesanato (ENTREVISTA 1A, 10/02/2016, p. 1-2). Esse relato reforça ainda mais o sentimento de pertencimento com o lugar, pois, assim como ela, outros irmãos nasceram, cresceram e constituíram família na "Aldeia Velha", além de ser um espaço onde conviveram com seus pais, irmãos e parentes.

É relevante salientar que, em 1990, o patriarca da Terra Indígena Jamã Tÿ Tãnh veio a falecer, e uma de suas filhas mais velhas assumiu a liderança do grupo, protagonizando importantes conquistas, sobretudo a partir de 2002. 
Processos de territorialidade Kaingang envolvendo a Terra Indígena Jamã Tÿ Tãnh, Estrela, Rio Grande do Sul, Brasil

Outra questão importante que nos foi informada em pesquisa de campo, diz respeito à relação da FUNAI com o grupo, quando ainda habitavam a "Aldeia velha". Segundo o depoimento de uma família indígena, em épocas passadas, quando ainda moravam na "Aldeia Velha", a FUNAI trazia cestas básicas completas, inclusive com frutas e galinha, porém, já há algum tempo que as cestas têm diminuído, não sendo suficientes, bem como o seu fornecimento ocorre de três em três meses (DIÁRIO DE CAMPO, 14/01/2016, p.04).

No ano de 2006, conforme informado anteriormente, o grupo passou a ocupar uma área de terras nova, sendo esta uma continuidade da "Aldeia Velha", pois foi incorporada à nova área. Vale destacar também que algumas famílias continuaram a ocupar a área da "Aldeia Velha" e que foi nesse espaço que o grupo conquistou, em 2002, o direito de ter uma escola indígena dentro da comunidade (LAROQUE; SILVA, 2013). Assim, as crianças continuaram a frequentar a escola inserida na "Aldeia Velha" até meados de 2013, quando então, ela foi transferida para o local ocupado em 2006, devido às obras de duplicação da BR 386 (DIÁRIO DE CAMPO, 30/08/2013, p. 1).

Verifica-se que esse grupo sempre manteve ligação com seus parentes oriundos de Terras Indígenas do norte do estado ou mesmo de outras Terras Indígenas situadas em contextos urbanos (SILVA; LAROQUE, 2012). Alguns inclusive passaram a estabelecer-se por longo período na Terra Indígena, enquanto outros permanecem por alguns meses, apenas para a venda do artesanato na região. Segundo Oliveira (1996), uma das causas da mobilidade indígena se deve ao fato de que as terras destinadas pelo governo aos grupos indígenas, não lhes assegura a sobrevivência, o que impõe como saída a migração temporária desses indígenas. Importante refletir também que essa questão revela que a mobilidade se faz enquanto prática cultural e que mesmo estabelecendo "Aldeia fixa”, o grupo da Terra Indígena Jamã Tÿ Tãnh continua a relacionar-se com seus parentes. Ou seja, para outros grupos Kaingang essa Terra Indígena pode representar o wãre contemporâneo, onde recebem abrigo por algum tempo para vender seu artesanato e depois retornarem para seu emã, revelando também certa negociação entre eles. À luz dessa questão, Oliveira (1996) destaca que não é da natureza indígena estabelecer limites territoriais para o exercício de sua sociabilidade. Sendo assim, mover-se pelo espaço é parte constitutiva das relações estabelecidas por essas sociedades entre si, como sempre fizeram, mesmo antes da chegada dos colonizadores.

Vemos também que a realidade da mobilidade se faz presente na Terra Indígena Jamã Tÿ Tãnh, onde algumas famílias deslocam-se de uma cidade a outra para vender seu artesanato em locais, como Montenegro e Lajeado, no Vale do Taquari, ou dirigem-se para cidades litorâneas de Tramandaí, no 
Rio Grande do Sul, e Laguna, em Santa Catarina, durante o período do verão (DIÁRIO DE CAMPO, 14/01/2016, p. 3).

Para tanto, se faz necessário compreender o território indígena enquanto um espaço contínuo onde os usos e costumes indígenas são colocados explícita e intencionalmente como prática de sua sociabilidade. Dessa forma, o território é onde vivem de acordo com suas metades e seções e segundo regras de reciprocidade, mas também é o espaço onde habitam os espíritos e outros seres sobrenaturais, é onde estão enterrados seus mortos e onde os vivos têm enterrado os seus umbigos (TOMMASINO, 2000). Vemos, portanto, que há uma concepção muito mais ampla de território, que não se insere numa definição político-administrativa. Nessa perspectiva, o território Kaingang possui uma dimensão sócio-político-cosmológica mais ampla (SEEGER; CASTRO, 1979).

Importante salientar que, na perspectiva de Cabral (2007), o território pode ser compreendido como um espaço mobilizado, e a territorialidade como a legitimidade para firmar o controle sobre um espaço geográfico. Dessa maneira, o território tem a ver com uma rede de relações vividas e, que não se faz necessário um enraizamento material para que determinado espaço seja concebido como território. Já a territorialidade é mais simbólica, é uma projeção da identidade e de elementos culturais sobre o território. Ilustram bem essa questão as concepções das populações indígenas que compreendem seus territórios com base em relações de sociabilidade que não comportam concepções fixas e fechadas de territórios demarcados, sem que haja qualquer relação social projetada.

Outra questão que acompanhou esse grupo durante a ocupação da "Aldeia Velha" e posteriormente, no novo espaço ocupado pela comunidade indígena em 2006, foi a presença de várias famílias em algumas moradias. Isto se deve por diversos motivos, dentre os quais podemos citar o fato de o número de famílias ser maior ao número de casas disponíveis, a vinda de famílias de outras Terras indígenas para residirem no local, o aumento demográfico do grupo, a realização de casamentos e a visita de parentes. Em janeiro de 2015, fomos informados de que o grupo estaria constituído por cerca de 32 famílias, distribuídas em 19 casas, totalizando cerca de 150 indivíduos (DIÁRIO DE CAMPO, 20/01/2015, p. 2).

É possível, de acordo com Cabral (2007), entender o "espaço geográfico" como uma categoria constituída e constituinte das relações humanas. Nesse sentido, a organização do espaço é produto da transformação e da experiência social, na medida em que as pessoas interagem, criam, recriam e atribuem significados a ele. Sendo assim, o espaço de sociabilidade Kaingang é mar- 
Processos de territorialidade Kaingang envolvendo a Terra Indígena Jamã Tÿ Tãnh, Estrela, Rio Grande do Sul, Brasil

cado por complexas interações que só podem ser vistas de forma dialética e em movimento.

Tommasino (2000) informa que o território Kaingang constituía um espaço de contínuos deslocamentos de subsistência material e reprodução social. Ilustram bem essa questão os dizeres a seguir:

Antes e mesmo nos primeiros tempos do contato, cada grupo local Kaingang possuía um subterritório próprio, com direito à exploração do mesmo, segundo regras determinadas culturalmente. As visitas entre parentes dos diferentes grupos locais eram muito frequentes e a recepção (à margem dos rios, na soleira da casa) era feita ritualmente. Portanto, uma sociedade Kaingang se distribuía em vários grupos locais formando subterritórios que eram socialmente integrados, e cada grupo possuía sua área de exploração, fato que remete para a existência de um código jurídico e para um conceito específico de propriedade territorial Kaingang, distinta do conceito capitalista de propriedade privada. (TOMMASINO, 2000, p. 195).

É possível constatar, portanto, que embora os Kaingang representem uma sociedade com grande mobilidade geográfica, havia também uma forma própria de se estabelecer no território definido socialmente. Outro aspecto importante destacado por Tommasino (2000) e que merece ser ressaltado, refere-se ao dinamismo das sociedades indígenas. Enquanto "sociedades vivas", estão sempre em movimentos internos e externos, não havendo sociedades estáticas seja temporal ou espacialmente. Assim, a configuração atual dos povos indígenas seria resultado de diferentes arranjos espaciais ao longo dos tempos, em acordo com as múltiplas "historicidades em permanente jogo".

Outro fato marcante que irá provocar mudanças na espacialidade territorial do grupo teve início em 2008, com a aprovação do empreendimento da duplicação da rodovia BR 386, no trecho entre Estrela e Tabaí, que, por ordem, afetaria a área da Terra Indígena, conhecida até meados de 2013 como "Aldeia Linha Glória". Ao que tudo indica, o nome foi uma referência feita pelos fóg à comunidade, pelo fato de localizar-se no bairro Linha Glória, em Estrela. Somente em 2013, por uma decisão da própria comunidade é que a Terra Indígena passaria a denominar-se "Jamã Tÿ Tãnh", significando "Morada do Coqueiro", ou "Aldeia do Coqueiro". Isto se deve ao fato de que, quando vieram a ocupar o espaço próximo à "Aldeia Velha", havia muitos coqueiros "que já moravam" no local (SCHWINGEL; LAROQUE; PILGER, 2014).

Conforme Silva e Laroque (2012) procuraram demonstrar através de seus estudos, o evento da duplicação da BR 386 traz para a visibilidade um

2 "Fóg" na língua Kaingang significa homem branco (TOMMASINO, 2004). 
grupo indígena como sujeito de direitos, o que provoca uma série de reações da sociedade em geral e dos gestores públicos. Dentre os desdobramentos desse evento, destaca-se a necessidade de realização de Estudos de Impacto Ambiental (EIA) e a consequente produção de um Relatório de Impacto Ambiental (EIA-RIMA), que trouxe para a pauta diversas questões. Dentre estas, podemos destacar a confirmação, a partir de estudos antropológicos da área ocupada pelo grupo, como sendo um tradicional território Kaingang, elemento importante para o reconhecimento do atual espaço como Terra Indígena pela União, bem como a concessão de uma série de medidas compensatórias e mitigatórias. Assim, as obras foram autorizadas pelo Instituto Brasileiro do Meio Ambiente e dos Recursos Naturais Renováveis (IBAMA), no final de 2009, e tiveram início em 2010 (SILVA; LAROQUE, 2012). Somente em 2013, é que uma área de terras de 6,7 hectares foi adquirida, um pouco mais ao sul do espaço ocupado em 2006, a fim de compensar as perdas sofridas pela supressão das terras da "Aldeia", sendo cumprida parte do que propõe o acordo, que é de 29 hectares. Em 2014, iniciou-se a construção de 29 casas de alvenaria e da Casa de Fala. Em julho de 2015, o grupo é realocado para esse novo espaço, mesmo sem a conclusão da escola e da Casa de Artesanato (FUNAI..., 2015, p. 9).

A partir dessa retrospectiva da movimentação do grupo, desde a saída de Santa Cruz do Sul, RS, até a sua efetiva instalação na cidade de Estrela, foi possível verificar que, por diversas questões relacionadas a segurança do grupo, melhorias nas condições de vida e moradia e posteriormente devido a um movimento externo, motivado pela duplicação da rodovia BR 386, os indígenas precisaram mover-se sobre o espaço geográfico, embora tivessem permanecido no seu tradicional território. Vimos, portanto, que a prática de migrar reatualiza-se conforme as necessidades de produzir sua vida, porém, assim como no passado, movimentar-se sobre o território sempre fez parte da lógica Kaingang.

Apoiados em Tommasino (2000), podemos ainda afirmar que os Kaingang da Terra Indígena Jamã Tü Tãnh se (re) territorializaram, na medida em que voltam a ocupar espaços que foram território de seus antepassados. Nesse espaço, continuam a manter parte de seus costumes antigos, que foram redefinidos, bem como foram inventando novos padrões, sempre de acordo com a lógica cultural Kaingang. Embora a necessidade os tivesse aproximado de contextos urbanos, evidenciando a presença de elementos da cultura nacional, há muitos aspectos que revelam uma especificidade própria do universo cultural e simbólico do jeito de ser Kaingang, que é vivido no cotidiano do grupo e em suas relações sociais. 


\section{O AVANÇO DE UMA FRENTE PIONEIRA SOBRE O TERRITÓRIO DA EMÃ JAMÃ TŸ TÃNH E AS RELAÇÕES DE MOBILIDADE E IDENTIDADE}

O termo "Frente Pioneira" foi utilizado pela primeira vez em 1940 por geógrafos, para referir-se a um movimento de caráter econômico que avança sobre um determinado espaço geográfico, a fim de atender a interesses capitalistas. Portanto há uma fronteira econômica pondo em contatos conflitivos populações, cujos antagonismos incluem o desencontro dos tempos históricos em que vivem (MARTINS, 1997).

Partindo dessa premissa inicial de frente pioneira, cunhada pelos geógrafos, que propomos pensar a duplicação da BR 386, que por ordem afeta diretamente o território da Terra Indígena Jamã Tÿ Tãnh e traz para o embate concepções, interesses e temporalidades históricas distintas. De um lado, estão os indígenas pensando a coletividade e o ambiente como um todo e, de outro, os interesses capitalistas de empresários e do poder governamental.

A duplicação da BR 386, no trecho entre Estrela e Tabaí, foi pensada sobretudo para fomentar o desenvolvimento econômico da região do Vale do Taquari. Conhecida como "Estrada da Produção", a BR 386 recebeu investimentos do Programa de Aceleração do Crescimento (PAC) do governo federal, para que pudesse concretizar-se. Assim, a rodovia tornou-se, ao nosso ver, uma "frente pioneira" que avança sobre o espaço ocupado pelos Kaingang da Jamã Tÿ Tãnh, provocando uma série de embates em relação à concretização das medidas compensatórias e mitigatórias previstas nos estudos de EIA/ RIMA, sobretudo no que diz respeito à aquisição da área de terras.

Importante salientar que parte da área ocupada pelos Kaingang, a partir de 2006, era de domínio federal, e outra parte, de propriedade particular (SILVA; LAROQUE, 2012). Assim, a duplicação reacende a questão da regularização da área de terras e prevê a compensação de 29 hectares para os Kaingang da Jamã Tÿ Tãnh, impactados diretamente por esse empreendimento, havendo a condição imposta pela FUNAI de que a questão das terras fosse resolvida e a nova "Aldeia" construída para que o trecho correspondente a 1,8 quilômetros da referida Terra Indígena, fosse liberado para realização das obras.

O Programa de Apoio às Comunidades Kaingang - Plano Básico Ambiental das obras de duplicação da BR 386 (ROSA, 2010), prevê "Áreas de Influência Direta" (AID) e "Áreas de Influência Indireta" (AII), havendo medidas compensatórias e mitigatórias que contemplam ambos os casos. Dessa forma, a Terra Indígena Foxá, situada em Lajeado e a Terra Indígena Jamã Tÿ Tãnh, em Estrela, são tidas como "Áreas de Influência Direta" (AID). 
Já as demais Terras Indígenas localizadas nas cidades de Farroupilha, São Leopoldo e Porto Alegre são consideradas "Áreas de Impacto Indireto". Isto se deve pela ligação que há entre as Terras Indígenas. Na concepção dos Kaingang, os lugares onde estão situadas essas Terras Indígenas não são concebidos como uma propriedade particular de determinado grupo. Elas são tidas como áreas coletivas. Assim, o que afeta uma área em específico afeta consequentemente a todos.

Dessa maneira, houve uma mobilização das lideranças Kaingang no sentido de promover alianças para fortalecer as lutas dessas comunidades indígenas em relação aos seus direitos, sobretudo, ao direito a terra. Por diversas vezes, houve a união dos líderes das Terras Indígenas impactadas pelas obras da duplicação para pressionar as autoridades competentes, seja a FUNAI, o Departamento Nacional de Infraestruturas de Transporte (DNIT) ou mesmo o Ministério Público, para que os acordos previstos fossem atendidos, principalmente relativo à aquisição das terras para as sete comunidades indígenas (CERTIDÃO, 17/12/2013).

Em janeiro de 2011, diante da possibilidade de remanejo dos Kaingang da Terra Indígena de Estrela, houve diversas reações do grupo, tendo em vista que não haviam sido consultados sobre a possibilidade de desocupação da área, uma vez que os acordos iniciais não eram estes (SILVA; LAROQUE, 2012). Há um apego simbólico sobre esse lugar, que se sobrepõe ao simples fato de migrar para outro espaço. Além disso, o Programa de Apoio às Comunidades Kaingang (ROSA, 2010), no subprograma fundiário, prevê que a escolha das áreas deverão ter a participação efetiva das comunidades indígenas, influenciando diretamente na escolha do local.

Embora as obras da duplicação tivessem iniciado em 2010, somente em 2013 é que a questão da aquisição de uma área de terras de 6,7 hectares ao lado do espaço ocupado pela comunidade indígena Jamã Tü Tãnh, foi resolvida, e, em dezembro, houve o fechamento com uma empresa contratada, que venceu a licitação para realizar a construção das benfeitorias (DNIT..., 2013, p. 10). Em janeiro de 2014, teve início a construção das casas, sendo praticamente concluídas em fevereiro de 2015 (OBRA..., 2015). Embora as casas já estivessem prontas em fevereiro, faltava a vistoria da FUNAI para a efetiva ocupação delas, o que não se concretizou de imediato devido à falta de recursos que impedia a mobilização de técnicos para o local.

Em julho de 2015, a ocupação da nova área ocorreu sob autorização do Ministério Público Federal, devido à ameaça de invasão de um grupo indígena Kaingang oriundo do norte do Estado (FUNAI..., 2015, p.9). Esse fato deve-se ao questionamento de indígenas da Terra Indígena Votouro, 
Processos de territorialidade Kaingang envolvendo a Terra Indígena Jamã Tÿ Tãnh, Estrela, Rio Grande do Sul, Brasil

em relação à identidade dos Kaingang da Jamã Tÿ Tãnh (NOTÍCIA de fato $\mathrm{n}^{\circ}$ 1.29.014.000075/2015-52). Essa questão se apresenta de forma bastante singular e demostra que as questões de embate entre parcialidades indígenas avançam para o século XXI, atendendo a questões históricas e culturais desses grupos. Laroque (2009), ao analisar a atuação de importante lideranças Kaingang em seus tradicionais territórios no século XIX, destaca, dentre outros aspectos, as disputas e conflitos existentes entre parcialidades nativas, o que demonstra que a questão da rivalidade sempre esteve presente entre alguns grupos indígenas.

Dessa forma, embora a questão envolva o reconhecimento da identidade étnica por outro grupo pertencente à mesma etnia, isto é perfeitamente aceitável já que o que está em jogo são conflitos de interesses. Porém pensar a questão da identidade indígena apoiada na interrogação feita por um mesmo grupo étnico é singular na medida em que envolve uma questão muito maior, que é o reconhecer-se enquanto grupo e ser reconhecido como tal.

Contribuiu para pensarmos essa questão os estudos de Stuart Hall (1992), para quem a identidade é um lugar que se assume em contexto. A identidade seria, sobretudo, o elo entre cultura e indivíduo. Sobre esse prisma, o Estatuto do Índio em seu artigo $3^{\circ}$ define, sob o termo "índio", o indivíduo que se identifica e é identificado como pertencente a um grupo étnico, cujas características culturais o distinguem da sociedade nacional (BRASIL, 1973). Da mesma forma, a Convenção 169 da Organização Internacional do Trabalho (OIT), em seu artigo $1^{\circ}$, reconhece como critério fundamental para a definição dos grupos, a autoidentificação como indígena ou tribal (BRASIL, 2011). Ou seja, basta que o próprio grupo se reconheça como indígena, para que a sua condição de identidade étnica tenha respaldo legal.

Mesquita (1994) destaca que a identidade é construída coletivamente e constituída socialmente no contato com o outro que é a parte antagônica de nós ou semelhante. A análise antropológica elaborada por Miriam Chagas em 2005, a pedido do Ministério Público Federal de Lajeado, reforça a autoidentificação do grupo como Kaingang e traz informações bastante valiosas de aspectos culturais analisados pela antropóloga em estudo de campo, quando ainda habitavam a "Aldeia Velha" (CHAGAS, 2005).

Geertz (2008) contribui no sentido de pensar o comportamento, próprio de uma cultura, como sendo fruto de um compartilhamento de códigos, símbolos, conceitos, ideias e concepções. Dessa forma, cultura e identidade estão ligadas, na medida em que se autoidentificar indígena tem a ver com práticas culturais compartilhadas no âmbito da sociabilidade desse grupo.

A questão da regularização da área ocupada pela Terra Indígena Jamã Tÿ Tãnh, embora tivesse seu processo legal iniciado em 2010, com a instauração 
de um Grupo Técnico (GT), não teve avanços significativos, passados 6 anos de sua instalação. Em documento disponibilizado pela FUNAI de Brasília, a pedido do Ministério Público Federal de Lajeado, solicitando informações sobre estudos de identificação e delimitação da referida Terra Indígena, aquele Órgão informa que, em 2010, fora constituído o Grupo de Trabalho (GT) com o objetivo de realizar estudos da referida área indígena, no entanto a análise técnica do relatório entregue, em novembro de 2010, à FUNAI considerou o documento insuficiente. E ainda, no que tange à regularização de uma área de terras para a comunidade Kaingang de Estrela, a FUNAI refere que se encontra em andamento o Programa de Apoio às Comunidades Kaingang, cujo documento prevê a aquisição de uma área de 33 hectares de terras e aponta o grande volume de reivindicações fundiárias em todo o país, iniciadas em anos anteriores, o que justificaria a escolha da FUNAI pela não abertura de novos Grupos Técnicos (OFÍCIO n. 319/DPT/2015).

Embora o documento referido anteriormente possa garantir, pelo menos em termos legais, o direito dessa comunidade de ter uma área de terras adquirida pela União, é fundamental que esta possa ser também reconhecida e demarcada legalmente como Terra Indígena. Sabemos que hoje as questões que dizem respeito ao direito indígena à terra, são bastante difíceis de serem equacionadas no Brasil e passam por longos processos jurídico-administrativos para de fato se concretizarem. Enquanto isso, os indígenas continuam a produzir suas vidas e lutar pela manutenção de sua cultura em mirradas porções de terras.

Em outro documento foi possível verificar uma posição diferente por parte da FUNAI de Brasília, frente à requisição feita Ministério Público Federal de Lajeado, do cronograma de ações relativas ao processo de identificação, delimitação e regularização do território indígena da comunidade Kaingang de Estrela, no qual consta o indicativo de elaboração de um novo Relatório de Fundamentação Antropológica da área que será realizado pela própria FUNAI. Após a entrega do referido relatório, com base em nova análise, a FUNAI informa que poderá então ser constituído um Grupo Técnico de identificação e delimitação da área nos "próximos exercícios", considerando critérios de planejamento adotados pela Coordenação Geral de Identificação e Delimitação da Diretoria de Proteção Territorial, pactuado em 2012 na Coordenação Regional de Passo Fundo (OFÍCIO n. 422/2015/PRES/FUNAI).

Os estudos de José de Souza Martins (1997) em relação ao tema da fronteira são importantes para pensarmos os embates frente à duplicação. Um dos grandes problemas de conflitos sociais relacionados à fronteira, no século XX e que se estende para o século XXI, é a questão da terra. Pensar a questão 
Processos de territorialidade Kaingang envolvendo a Terra Indígena Jamã Tÿ Tãnh, Estrela, Rio Grande do Sul, Brasil

indígena atualmente é pensar na garantia de um espaço territorial que lhes dê condições de sustentabilidade e de viver de acordo com suas pautas culturais. Assim, ao discutir a questão indígena, discute-se o direito à terra, sendo esta uma questão bastante difícil de ser equacionada no Brasil, tendo em vista que a relação indígena com a terra não se pauta por uma questão econômica, mas, sobretudo, cultural. Não é uma questão de reforma agrária, mas de preservação da sociobiodiversidade e dos elementos encantados presentes nas matas, da garantia de acessar materiais para confecção do artesanato, de acessar os chás e plantas de sua cultura tradicional, de poder continuar a reproduzir-se enquanto etnia indígena.

A fronteira é, na perspectiva de Martins (1997), o lugar da alteridade, das diferenças de concepções, das diferentes visões de mundo. Assim, ao avançar sobre o território da Jamã Tü Tãnh, a BR 386 contrasta com opiniões divergentes em relação ao que seja "desenvolvimento". Como uma frente pioneira, a rodovia representa um movimento em prol do capital. No entanto, quando questionamos os Kaingang sobre sua concepção de desenvolvimento, vemos uma ideia que não se pauta por uma questão econômica, mas, sim, humana, em que há uma preocupação com a vida de todos os seres e com a coletividade que será afetada (ENTREVISTA 1A, 10/02/2016).

Atualmente existe um movimento das lideranças no sentido de definir uma outra área que deverá ser adquirida no município de Farroupilha, e que servirá para compensar o restante dos 33 hectares acordados como medida compensatória. Segundo informações preliminares, a ideia das lideranças é que algumas famílias possam migrar para Farroupilha, a fim de ocupar o local, e que essa nova área sirva de referência para a busca de matéria prima para a confecção de artesanato, pois atualmente os indígenas precisam caminhar longas distâncias para conseguir material, sendo estes coletados às margens de rodovias estaduais e federais (DIÁRIO DE CAMPO, 19/05/2016).

Conforme procurou-se demonstrar, a duplicação da BR 386 provocou rearranjos na espacialidade da Terra Indígena Jamã Tÿ Tãnh. Vimos, no entanto, que as lideranças reagiram para que sua alteridade e concepções de território e territorialidade fossem respeitadas e consideradas na permanência nesse lugar. Embora diversas fronteiras estejam postas na sociedade nacional, vemos que o avanço do século XXI traz um movimento de reatualização dessas fronteiras e dos espaços ocupados pelos indígenas. Embora possamos concordar com Martins (1997) sobre o fato de que a história da fronteira é uma história de destruição, sobretudo dos povos indígenas, há que se dizer também que esses sujeitos buscam reagir como podem para que sua alteridade seja respeitada. 


\section{CONSIDERAÇÕES FINAIS}

Neste estudo, nos propusemos a discutir os processos de territorialidade, sentidos e práticas pelos quais os Kaingang da Terra Indígena Jamã Tÿ Tãnh têm firmado sua relação de pertencimento com o espaço ocupado. Vimos que a territorialidade do grupo tem a ver com a apropriação simbólico-cultural do espaço e com o fortalecimento de suas identidades culturais. Dessa forma, ao mover-se no e sobre o espaço, o grupo Kaingang da Jamã Tü Tãnh continuou a manter muitos de seus costumes antigos. Entender as práticas culturais dessa sociedade indígena possibilita ampliar a compreensão de que são sociedades dinâmicas, o que faz com que haja movimentos impulsionados tanto internamente, quanto no contato com outros grupos, caracterizados pelas frentes de expansão, ou mesmo pelo avanço da chamada "modernização", através das frentes pioneiras. Procuramos demonstrar também que a luta pela terra é um processo que vem de longa data e que continua pulsante frente à duplicação da rodovia BR 386. Os desdobramentos desse evento ainda não finalizaram, por isso, este continua sendo um processo em curso.

Apesar de todo o avanço da Constituição Federal de 1988, na tentativa de legitimar os territórios indígenas, vemos o poder da fronteira econômica minimizando e reduzindo cada vez mais as condições sociais e ambientais dos indígenas que lutam para fazer valer seus direitos, sobretudo o direito à terra, garantidos sob forte mobilização étnica e em processos jurídico-administrativos bastante demorados. A duplicação da rodovia BR 386 afeta diretamente o ambiente como um todo, visando atender uma racionalidade econômica da sociedade nacional. Percebemos que as coletividades indígenas vivenciam outra racionalidade que não é pautada no acúmulo, mas, sim, na garantia de um ambiente melhor para as gerações futuras.

\section{REFERÊNCIAS}

BECKER, Ítala Irene Basile. O indio Kaingáng no Rio Grande do Sul. São Leopoldo, RS: Ed. UNISINOS, [1976] 1995.

BRASIL. Lei 6.001/1973 (LEI ORDINÁRIA) 19/12/1973. Dispõe sobre o Estatuto do Índio. Disponível em: <http://www.planalto.gov.br/ccivil_03/leis/L6001.htm>. Acesso em: 28 maio 2016.

. Convenção 169 sobre os povos indígenas e tribais e Resolução referente à ação da OIT/Organização Internacional do Trabalho. Brasília: OIT, 2011. Disponível em: <http:/ / portal.iphan.gov.br/uploads/ckfinder/arquivos/Convencao_169_OIT.pdf $>$. Acesso em: 28 maio 2016. 
Processos de territorialidade Kaingang envolvendo a Terra Indígena Jamã Tÿ Tãnh, Estrela, Rio Grande do Sul, Brasil

BUSOLLI, Jonathan. A Terra Indígena Pó Mág, Tabaí/RS no contexto da reterritorialidade Kaingang em áreas da Bacia Hidrográfica Taquari-Antas. 2015. 121 f. Monografia (Graduação em História) - Centro Universitário Univates, Lajeado, RS, 2015.

CABRAL, Luiz Otávio. Revisitando as noções de espaço, lugar, paisagem e território, sob uma perspectiva geográfica. Revista de Ciências Humanas, Florianópolis, v. 41, n. 1 e 2, p. 141-155, abr./out. 2007.

CERTIDÃO de 17/12/2013. Inquérito Civil n ${ }^{\circ}$ 1.29.014.000070/2009-81. In: INQUÉRITO CIVIL MINISTÉRIO PÚBLICO FEDERAL. Lajeado, RS, 17 dez. 2013.

CHAGAS, Miriam. Análise da analista pericial em antropologia sobre a comunidade Kaingang de Estrela. Lajeado, RS: Ministério Público Federal, 2005. 34p.

DIÁRIO DE CAMPO. Pesquisa de Campo na Terra Indígena Jamã Tü Tãnh. Projeto de Extensão História e Cultura Kaingang em Territórios da Bacia Hidrográfica Taquari-Antas. Lajeado: Univates, 19 maio 2016. 4 p.

. Pesquisa de Campo na Terra Indígena Jamã Tü Tãnh. Estrela, RS. Projeto de Extensão História e Cultura Kaingang em Territórios da Bacia Hidrográfica Taquari-Antas. Lajeado: Univates, 14 jan. 2016. 5 p.

. Pesquisa de Campo na Terra Indígena Jamã Tÿ. Tãnh. Estrela, RS. Projeto de Extensão História e Cultura Kaingang em Territórios da Bacia Hidrográfica Taquari-Antas. Lajeado: Univates, 20 jan. 2015. 4 p.

. Pesquisa de Campo na Terra Indígena Jamã Tÿ. Tãnh. Estrela, RS. Projeto de Extensão História e Cultura Kaingang em Territórios da Bacia Hidrográfica Taquari-Antas. Lajeado: Univates, 30 ago. 2013. 3 p.

DNIT quer pressionar Funai para liberação de obra de duplicação. O Informativo do Vale, Lajeado, RS, p. 10, 12 dez. 2013.

ENTREVISTA 1A: depoimento [10 fev. 2016, 10 p.]. Terra Indígena Jamã Tÿ Tãnh, Estrela, RS. Gravação em gravador digital. Entrevista concedida a Ernesto Pereira Bastos Neto, Projeto de Extensão História e Cultura Kaingang em Territórios da Bacia Hidrográfica Taquari-Antas. Lajeado: Univates, 2016.

ENTREVISTA EC: depoimento [17 mar. 2011, 5 p.]. Terra Indígena Jamã Tÿ Tãnh, Estrela, RS. Gravação em gravador digital. Entrevista concedida a Ernesto Pereira Bastos Neto, Lajeado: Univates, 2011.

FUNAI promete liberar obras na BR 386 na próxima semana. Jornal a Hora, Lajeado, RS, p. 09, 25/26 jul. 2015.

GEERTZ, Clifford. A interpretação das culturas. Rio de Janeiro: LTC, [1926] 2008.

GONÇALVES, Jaci Rocha. Relatório Final Antropologia na área de duplicação da BR386, Triunfo, Tabaí, Taquari, Fazenda Vila Nova, Bom Retiro do Sul e Estrela - RS Aldeia Kaingang TI Estrela. Tubarão: UNISUL, 2008. (Participação de Alexandre Magno Aquino).

HALL, Stuart. A identidade cultural na pós-modernidade. Rio de Janeiro: DP\&A, 1992. 
LAROQUE, Luís Fernando da Silva; SILVA, Juciane Beatriz Sehn da. Ambiente e cultura Kaingang: saúde e educação na pauta das lutas e conquistas dos Kaingang de uma Terra Indígena. Educação em Revista, Belo Horizonte, v. 29, n. 02, p. 253-275, jun. 2013. Disponível em: <http://www.scielo.br/scielo.php>. Acesso em: 6 out. 2015.

LAROQUE, Luís Fernando da Silva. Fronteiras geográfica, étnicas e culturais envolvendo os Kaingang e suas lideranças no sul do Brasil (1889-1930). Pesquisas, Antropologia, São Leopoldo, RS, n. 64, 343p., 2007.

. Os Kaingangues - momentos de historicidades indígenas. In: GOLIN, Tau; BOEIRA, Nelson (Coord.). História - Rio Grande do Sul - Povos indígenas. Passo Fundo, RS: Méritos, 2009. v. 5, p. 81-108.

MARTINS, José de Souza. Fronteira: a degradação do outro nos confins do humano. São Paulo: Hucitec, 1997.

MESQUITA, Zilá. Procura-se o coração dos limites. In: LEHNE, Carlos; CASTELO, Iara Regina; SCHAFER, Neiva Otero (Org.). Fronteiras no Mercosul. Porto Alegre: UFRGS/ Edições Prefeitura Municipal de Uruguaiana, 1994, p. 69-73.

NOELLI, Francisco Silva. A ocupação humana no sul do Brasil: arqueologia, debates e perspectivas 1872-2000. Revista USP, São Paulo, n. 44, p. 218-269, dez./fev. 1999-2000.

NONNENMACHER, Marisa Schneider. Aldeamentos Kaingang no Rio Grande do Sul: século XIX. Porto Alegre: EDIPUCRS, 2000.

NOTÍCIA de fato n. 1.29.014.000075/2015-52. In: INQUÉRITO CIVIL MINISTÉRIO PÚBLICO FEDERAL DE LAJEADO, 3 jul. 2015. 20 p.

OBRA de duplicação da BR 386 pode parar. Jornal A Hora. Disponível em: <http:/ / www.jornalahora.com.br/cidades/2015/01/30/obra-de-duplicacao-da-br-386-pode-parar>. Acesso em: $1^{\circ}$ fev. 2016.

OFÍCIO n. 319/DPT/2015. Reivindicação fundiária Kaingang de Estrela. In: INQUÉRITO CIVIL MINISTÉRIO PÚBLICO FEDERAL DE LAJEADO. 28 abr. 2015. 2p.

OFÍCIO n. 422/2015/PRES/FUNAI. Inquérito Civil n 1.29.014.000064/2014-91. In: INQUÉRITO CIVIL MINISTÉRIO PÚBLICO FEDERAL DE LAJEADO. 25 set. 2015. 2p.

OLIVEIRA, João Pacheco de. Viagens de ida, de volta e outras viagens: os movimentos migratórios e as sociedades indígenas. Travessia: Revista do Migrante, São Paulo, ano IX, n. 24, p. 5-10, jan./abr. 1996.

ROSA, Alexandre Nunes da. Programa de Apoio às Comunidades Kaingang - Plano Básico Ambiental das Obras de Duplicação da Rodovia - BR 386: Km 350,8 - 386,0. Brasília: MRS Estudos Ambientais, 2010.

SCHWINGEL, Kassiane; LAROQUE, Luis Fernando da Silva; PILGER, Maria Ione. Jamã Tý Tãnh. Ig Vênh vêj Kaingag. Morada do Coqueiro. Jeito de viver Kaingang. São Leopldo, RS: Oikos, 2014. 
Processos de territorialidade Kaingang envolvendo a Terra Indígena Jamã Tÿ Tãnh, Estrela, Rio Grande do Sul, Brasil

SEEGER, Anthony; CASTRO, Eduardo B. Viveiros. Terras e territórios indígenas no Brasil. Rio de Janeiro: Civilização Brasileira, 1979. (Col. Encontros com a Civilização Brasileira, n. 12, p. 101-109).

SIDEKUM, Antonio (Org.). Alteridade e multiculturalismo. Ijuí, RS: Ed. Unijuí, 2003.

SILVA, Juciane Beatriz Sehn. Territorialidade Kaingang: um estudo da aldeia Kaingang Linha Glória, Estrela - RS. 125 f. Monografia (Graduação em História) - Centro Universitário Univates, Lajeado, RS, 2011.

SILVA, Juciane Beatriz Sehn da; LAROQUE, Luís Fernando da Silva. A história dos Kaingang da Terra Indígena Linha Glória, Estrela, Rio Grande do Sul/Brasil: sentidos de sua (re) territorialidade. Sociedade e Natureza, Uberlândia, MG, v. 24, n. 03, p. 435-448, set./dez. 2012. Disponível em: <http://www.seer.ufu.br/index.php/ sociedadenatureza/article/view/15008>. Acesso em: 6 out. 2015.

TOMMASINO, Kimiye. Território e territorialidade Kaingang: resistência cultural e historicidade de um grupo Jê. In: MOTA, Lúcio Tadeu; NOELLI, Franciso S.; TOMMASINO, Kimiye (Org.). Urí e Wãxí - estudos interdisciplinares dos Kaingang. Londrina, PR: UEL, 2000. p. 191-224.

. Homem e natureza na ecologia dos Kaingang da bacia do Tibagi. In: TOMMASINO, Kiniye; MOTA, Tadeu; NOELLI, Francisco Silva. Novas contribuições aos estudos interdisciplinares dos Kaingang. Londrina, PR: Eduel, 2004.

VEDOY, Moisés Ilair Blum. Contatos interétnicos: sesmeiros, fazendeiros, imigrantes alemães e indígenas Kaingang em Territórios das Bacias Hidrográficas do Taquari-Antas e Caí. 2015. 100 f. Monografia (Graduação em História) - Centro Universitário Univates, Lajeado, RS, 2015. 
